\title{
Energy recovery from two-stage SWRO plant using PRO without external freshwater feed stream: theoretical analysis ${ }^{1}$
}

\author{
Khaled Touati ${ }^{\mathrm{a}, \mathrm{b}^{*}}$ \\ ${ }^{a}$ Department of Systems Engineering and Automatic Control, University of Valladolid, \\ 47011, Valladolid, Spain. Tel: +34 983423162; Fax: +34 98342316. \\ ${ }^{b}$ Laboratory of Natural Water Treatment- Water Researches and Technologies Center, \\ Techno-park Borj Cedria, BP 273, 8020, Soliman, Tunisia. Tel: + 21679325122 / \\ 79325199; Fax: + 216 79325802. ${ }^{*}$ Corresponding author: kha.touati@gmail.com

\section{Jacobo Salamanca $^{\mathrm{a}}$}

${ }^{a}$ Department of Systems Engineering and Automatic Control, University of Valladolid, 47011, Valladolid, Spain. Tel: +34 983423162; Fax: +34 983423161. fernando@autom.uva.es

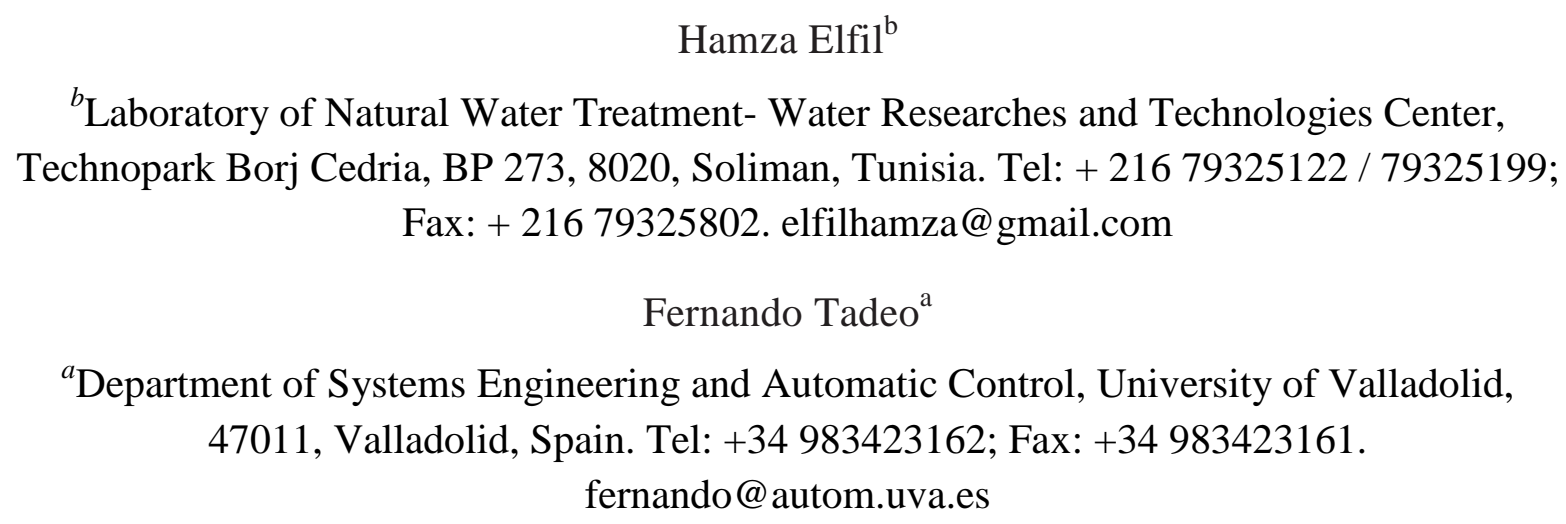

${ }^{b}$ Laboratory of Natural Water Treatment- Water Researches and Technologies Center, Technopark Borj Cedria, BP 273, 8020, Soliman, Tunisia. Tel: + 21679325122 / 79325199 ; Fax:+216 79325802. elfilhamza@gmail.com

\section{Fernando Tadeo ${ }^{\mathrm{a}}$}

${ }^{a}$ Department of Systems Engineering and Automatic Control, University of Valladolid, 47011, Valladolid, Spain. Tel: +34 983423162; Fax: +34 983423161. fernando@autom.uva.es

\footnotetext{
${ }^{1}$ Funded by Mineco Project DPI2014-54530-R and FEDER funds
} 
PREPRINT Renewable Energy, Volume 105, May 2017, Pages 84-95

DOI: 10.1016/j.renene.2016.12.030

1

\section{Abstract:}

3 Research into pressure retarded osmosis (PRO) as a method to extract energy from salinity

4 gradients is on the rise. Seawater Reverse Osmosis (SWRO) is now a leading technology in

5 the desalination industry worldwide, in both small and large scale applications, due to the remarkable improvements in membrane performance and associated energy efficiency. Nonetheless, SWRO desalination is inherently more energy intensive when compared to conventional fresh water treatment. The integration of PRO with SWRO systems is studied in terms of energy consumption and effluent changes. For this, two novel integration designs are evaluated, with SWRO-PRO specific energy consumption being modeled using SWRO conditions at the thermodynamic restriction, and a developed PRO model. The results show lower SWRO energy consumption for both configurations, with a reduction in consumption of $12 \%$ to $18 \%$, depending on the RO recovery ratios. Lastly, the effect of the initial flow ratio on the dilution factor has been studied. To do so, the dilution was modeled and studied for different operating conditions. It was found that detrimental effects severely reduce the dilution, especially the internal concentration polarization, which induces a decrease of energy recovery when using the PRO process.

Keywords: Pressure Retarded Osmosis; Seawater Reverse Osmosis; Energy recovery; Modeling; Dilution Factor.

(1)

(1)

(2)

3




\section{Energy recovery from two-stage SWRO plant using PRO without external freshwater feed stream: theoretical analysis.}

\section{Introduction}

Desalination technologies are quickly growing, combining engineering and science to develop innovative means for drinkable water production [1]. In fact, several countries, especially in the Middle East, already depend on seawater desalination as the main source of drinking water [2,3], so desalination plants have seen considerable expansion over the past decade: the desalination capacity is expected to reach about 100 million cubic meters per day at the end of 2016 [2]. The main challenge in desalination is the use of energy: As a drinking water treatment technology, seawater desalination requires more energy than conventional fresh water treatment methods [3]. However, the power consumption is frequently inaccurately represented when compared to other treatment technologies that provide safe and reliable public water supply [4, 5]. Typically, the energy consumption represents $44 \%$ of the total water cost of a SWRO plant [6]. Another challenge in the desalination industry is the handling of reject brine, which is the highly concentrated by-product of the desalination process $[7,8]$. Osmotic Energy systems were proposed as a solution due to the fact that it has been found to be very promising, with the potential of reducing the cost of seawater desalination as well as the environmental impact from brine discharge $[9,10,11]$. In other words, as a SWRO system produces high water concentration (brine) and PRO uses solutions with high concentrations, it would be beneficial to hybridize the two processes due to the reliance of the two membrane processes on the concentration of solutions. In addition, The SWRO-PRO system has several advantages. Compared to an optimized stand-alone SWRO system (SWRO with a recovery energy device), SWRO energy consumption is reduced by energy production using PRO [12]. Another advantage of this system is that the brine generated during the SWRO process is diluted back to seawater concentration, thus minimizing the adverse environmental impact that seawater RO brine disposal can have on marine ecology/habitats. Furthermore, the impaired water and SWRO product water are in separate circuits, so there is no contact between impaired water and drinking water. Compared to a stand-alone PRO system (i.e., river-to-sea PRO), PRO energy production in the SWRO-PRO system is augmented by the higher concentration of the draw solution (SWRO brine). Another key advantage of the SWRO-PRO system is that the influent draw solution is pre-treated by the RO pre-treatment system. Thus, the brine entering the PRO sub-system is relatively free of foulants. This 
PREPRINT Renewable Energy, Volume 105, May 2017, Pages 84-95

DOI: 10.1016/j.renene.2016.12.030

1 draw solution pre-treatment in the SWRO-PRO system avoids additional energy expenditure that would be necessary in a stand-alone PRO system. As the energy and chemical costs of pre-treating seawater is a substantial operating expenditure in SWRO desalination [13], the fact that SWRO-PRO capitalizes on the pre-treated brine reduces some pre-treatment concerns, which can be significant in the PRO process. As a consequence of these encouraging advantages, the integration of PRO into SWRO has attracted the attention of many researchers and several studies are currently involved in investigating the feasibility of SWRO-PRO systems [14,15,16,17,18]. In 2010, Japan launched the Megaton water system. As part of the project, a prototype SWRO-PRO hybrid plant was built and operated. Recycled water was supplied from a regional sewage treatment facility and concentrated brine from a SWRO plant, using PRO hollow fiber modules. The prototype PRO plant got the maximum output power density of $13.8 \mathrm{~W} / \mathrm{m}^{2}$ at 30 bars of hydraulic pressure difference, corresponding to $38 \%$ permeation of pure water into the brine [14]. Another study was carried out using an experimental pilot system, designed and constructed to investigate the reduced SWRO energy consumption by its integration with PRO $[15,16]$. The experiments showed that the enhanced power densities for the RO-PRO system ranged from 1.1 to $2.3 \mathrm{~W} / \mathrm{m}^{2}$ and indicated that future RO-PRO systems may reduce the specific energy consumption requirements for desalination by $1 \mathrm{kWh} / \mathrm{m}^{3}$ [16]. Another work investigated the feasibility of a RO desalination system powered by a stand-alone PRO unit [17]. Unfortunately, the study did not take into consideration the effect of the concentration polarization and the salt reverse flux on the performance of the SWRO-PRO system, which would affect the results. Seawater brine from the TuaSpring desalination plant and wastewater retentate from the NEWater plant were used in [18] for energy recovery. Experiments gave a power density of $4.6 \mathrm{~W} / \mathrm{m}^{2}$ at 20 bar obtained with seawater brine as the draw solution and waste water as the feed solution. A recent paper investigated two SWROPRO designs based on the positions of the pressure exchangers and the pump, then studied as a function of SWRO recovery [19].

However, most of the previously studied SWRO-PRO cases deal with conventional integration design, where one-stage SWRO brine is the PRO draw solution and a river water/wastewater effluent is the PRO feed solution. This integration methodology reveals that the amount of energy produced is relatively low and requires a feed solution from a low salinity water source, which increases the energy cost (pre-treatment, installations, etc...). Moreover, previous studies have been based on supplying the PRO with external freshwater sources. However, it is well known that the world is facing a serious fresh water scarcity 
PREPRINT Renewable Energy, Volume 105, May 2017, Pages 84-95

DOI: 10.1016/j.renene.2016.12.030

1 problem [20]. Then, the use of fresh water for energy recovery should be avoided.

2 Furthermore, the use of wastewater effluents shows low energy recovery performance, due

3 to the severe membrane fouling and the necessity for pre-treatment, which increases the energy consumption [18]. In this study, for the first time, an operational two-stage SWRO unit is integrated with PRO to reduce its energy consumption. Herein, the use of an external feed water source is avoided, and an alternative location of the PRO inside the process is proposed. To do so, two novel SWRO-PRO designs have been proposed in terms of the PRO location and the nature of the feed solution. To accomplish this objective, a model for the PRO system has been developed, taking into consideration the membrane characteristics, reverse salt flux, concentration polarization, and pressure drop in the membrane module. The SWRO specific energy consumption is calculated by considering the SWRO at its thermodynamic limit, using models from the literature [21]. Then, the SWRO-PRO model was developed by combining the SWRO and PRO models. In addition, the results of the model were presented for both configurations considered and compared to the ideal case. Lastly, the dilution factor of the draw solution was modeled and investigated as a function of PRO detrimental effects.

\section{Material and method}

\subsection{Description of the SWRO desalination plant}

To investigate the feasibility of PRO integration with the SWRO unit, a case study is considered here. A Reverse-Osmosis based desalination unit is used, intended for producing water for the electrolyzation process, and which is composed of the elements presented in Fig.1. This plant was developed by SETA S-L as a part of the H2OCEAN project [22]. The desalination unit is based on two independent lines, divided into two stages, which can be connected or disconnected, as required for maintenance or operational requirements. In order to reduce the number of spare parts required, both lines have the same components. The procedure is started by a pre-treatment composed of three steps: chlorination to avoid organic matter, ultra-filtration to block metals and particles in suspension, and finally, a backwash to eliminate foulants accumulated on the membrane surfaces during the process.

The first pass of the SWRO unit consists of a chemical treatment applied to remove the residual chlorine from the pre-treatment, then bisulphite is used (to remove the oxidants dissolved in the water and provide a bacteriostatic effect) and, finally, antifouling is used to mitigate salt precipitation on the membrane surfaces to avoid the increase in energy 
PREPRINT Renewable Energy, Volume 105, May 2017, Pages 84-95

DOI: 10.1016/j.renene.2016.12.030

1 consumption. As a safety system to avoid damaging the membrane, a micro filter is installed

2 just before the High Pressure Pump (HP) with a degree of 5 microns of filtration. To feed the

3 first-pass membranes, an HP is required; the water produced is stored in a water tank, whereas

4 the brine goes to an Energy Recovery system (Pressure exchanger PX). In routine operational

5 conditions, the recovery factor is arbitrarily selected to be $45 \%$.

6 The Second RO Pass consists of two phases, it is first dosed with an antifouler designed to avoid salt precipitation and a micro filter is installed with a degree of 5 microns of filtration, as a safety system to avoid membrane fouling. Second, to feed the second-pass, the RO requires an HP to pressurize the water before it enters the membrane. The reverse osmosis recovery is around $70 \%$. The water produced is stored in a DEMI water tank, whereas the brine goes to an energy recovery system before being reused in the proposed osmotic energy recovery system or being returned to the Ultra-Filtration Tank.

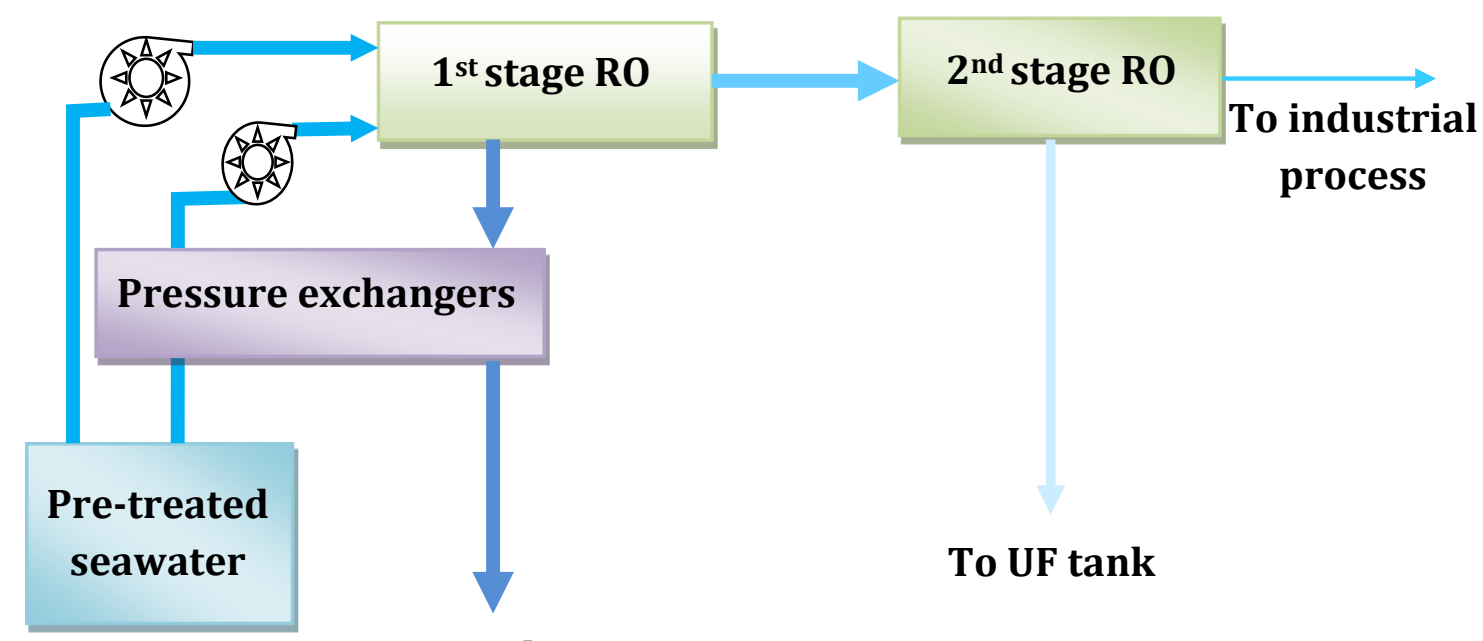

\section{Brine to the sea}

Fig.1: Two-stage Reverse Osmosis desalination unit

\subsection{SWRO-PRO configurations and integration methodologies}

\subsubsection{First SWRO-PRO configuration}

A simplified presentation of the first SWRO-PRO configuration is illustrated in Fig.2: the seawater feed solution $\left(\mathrm{Q}_{\mathrm{sw}}\right)$ is first pre-pressurized in the pressure exchanger PX prior to entering the desalination process. Exiting the first stage SWRO sub-system $\left(\mathrm{RO}_{1}\right)$ are two streams: a freshwater permeate stream $\left(Q_{p}\right)$ and a concentrated brine stream $\left(Q_{R 1}\right)$. $Q_{S R 1}$ is then depressurized to approximately half its pressure to reach an adequate condition for the 
PREPRINT Renewable Energy, Volume 105, May 2017, Pages 84-95

DOI: 10.1016/j.renene.2016.12.030

1 PRO process [7]. The permeate of the $\mathrm{RO}_{1}$ feeds the second stage $\mathrm{RO}$ sub-system $\left(\mathrm{RO}_{2}\right)$. To

2 recover the brine energy, an isobaric or turbocharged device could be used; alternatively, a

3 turbine could be employed to convert it into electrical energy. Following this

4 depressurization, the brine stream enters the PRO sub-system as a high salinity (draw)

5 solution $\left(Q_{R 1}=Q_{D}\right)$. The feed solution for the $P R O$ sub-system $\left(Q_{F}=Q_{R 2}\right)$ is the retentate of

6 the second stage. Through osmosis, the pressurized draw solution extracts water from the

7 impaired water source under isobaric conditions, resulting in a diluted draw solution (Q $\left.\mathrm{Q}_{\mathrm{DR}}\right)$.

8 The energy stored in the diluted draw solution is then exchanged with the seawater RO feed

9 prior to discharge in order to recover its potential energy and increase the energy savings of the SWRO-PRO system. The PRO feed solution bleed $\mathrm{Q}_{\mathrm{FR}}$ is rejected to the sea.

\subsubsection{Second SWRO-PRO configuration}

In the second configuration, the feed solution entering the PRO sub-system was changed. The retentate of the second stage $\left(\mathrm{Q}_{\mathrm{R} 2}\right)$ was mixed with an additive pre-treated seawater flow $\left(\mathrm{Q}_{\mathrm{ad}}\right)$; the sum embodies the PRO feed solution. The amount of seawater flow is chosen to 
PREPRINT Renewable Energy, Volume 105, May 2017, Pages 84-95

DOI: 10.1016/j.renene.2016.12.030

1 guarantee the condition that the feed and draw solution flows are equal $\left(Q_{F}=Q_{a d}+Q_{R 2}=Q_{D}\right)$.

2 For this, a controllable valve (V) is placed to provide the desired amount of $\mathrm{Q}_{\mathrm{ad}}$. The draw

3 solution of the PRO is the brine of the first RO stage; this brine passes through the energy recovery device (ERD) to adjust its pressure, when necessary, to a suitable applied pressure value (which is theoretically the optimum pressure value to be applied to the draw solution in the PRO process). It should be noted that the functioning of the ERD in this configuration is studied later, in section 2.4.3. The exiting PRO draw solution flow is then conducted to the PX to recover the pressure to the feed SWRO flow $\left(\mathrm{Q}_{\mathrm{sw}}\right)$. The PRO feed solution bleed $\mathrm{Q}_{\mathrm{FR}}$ is rejected to the sea. Fig.3 illustrates the second SWRO-PRO configuration. It should be pointed out that the choice of seawater as an added flow to the entering PRO feed solution is based on the fact that the SWRO plant is placed near the sea, and no river water is close to the SWRO facility.

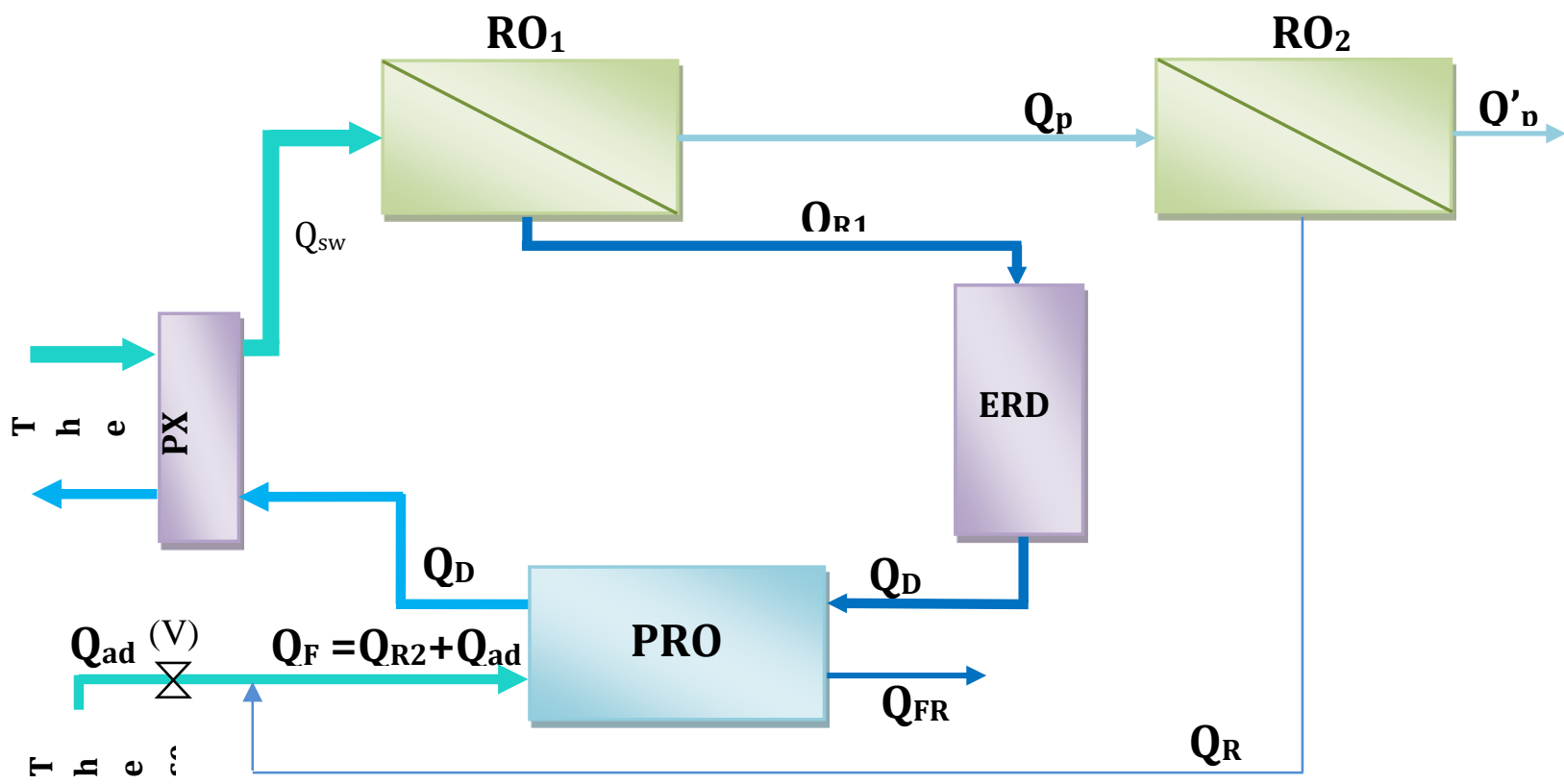

Fig. 3: Second configuration SWRO-PRO integration: standard with second brine-seawater mixture. Darker colors correspond to more concentrated solutions and the thickness of each arrow denotes the approximate flow rate.

\subsection{Modeling the ideal energy consumption of the SWRO-PRO system}

\subsubsection{Two-stage Reverse Osmosis (SWRO)}

The theoretical energy consumption is the minimum amount of energy required to produce a desired volume of permeate. More precisely, the theoretical Specific Energy Consumption 
PREPRINT Renewable Energy, Volume 105, May 2017, Pages 84-95

DOI: 10.1016/j.renene.2016.12.030

1 (SEC) gives, for a given recovery rate, the absolute minimum amount of energy by assuming that the efficiency of every component (pumps, motors, Energy Recovery Devices, etc.) is $100 \%$. At the theoretical limit of constant-pressure operation, the one-stage reverse osmosis (RO) system will operate with an applied hydraulic pressure equal to the final osmotic pressure of the brine exiting the RO module. Thus, the minimum specific energy of

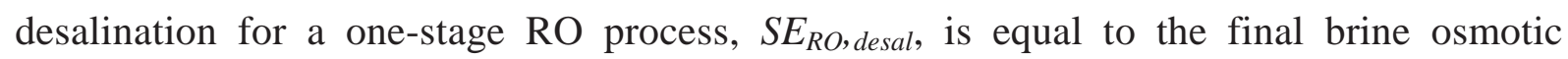
pressure [21,30]: In our case, considering two RO stages, the total theoretical energy consumption of the two-stage $\mathrm{RO}$ system $\left(S E C_{R O_{1}-R O_{2}, \text { theo }}\right)$ is the sum of the energy consumption of each stage:

$$
S E C_{R O_{1}-R O_{2}, \text { theo }}=\pi_{S w}\left(\frac{1}{1-Y_{1}}+\frac{Y_{1}}{1-Y_{2}}\right)
$$

where $Y_{1}$ and $Y_{2}$ are the recoveries of $\mathrm{RO}_{1}$ and $\mathrm{RO}_{2}$, respectively. The salt rejection coefficient $R_{s}$ for both RO stages is defined as:

$$
R_{s 1}=1-\frac{C_{p}}{C_{s w}}
$$

$$
R_{S 2}=1-\frac{C_{p^{\prime}}}{C_{p}}
$$

where $C_{p}$ and $C_{p^{\prime}}$ are the salt concentration in the permeate solutions of the first and second stages, respectively. For simplicity, the salt rejection coefficients are considered equal $\left(\mathrm{R}_{\mathrm{s} 1}=\mathrm{R}_{\mathrm{s} 2}=\mathrm{R}_{\mathrm{s}}\right)$. Throughout the study, a linear relation between salt concentration and osmotic pressure, based on the van't Hoff equation, is assumed $(\pi=\beta R T C)$. This assumption makes the development of simple analytical expressions easy, without a significant compromise in accuracy, because a concentration relevant to seawater $\left(C_{s w}=35 g / L\right)$ is low enough for the van't Hoff equation to be reasonably accurate. Fig. S1 (Supplementary material) describes the minimum separation energy for a two-stage SWRO as a function of $\mathrm{Y}_{1}$ according to Eq. (1), which is achievable only in an ideal, reversible, thermodynamic process. In this case, since the majority of the energy is consumed by the first stage, the recovery of the second stage is maintained equal to $70 \%$ throughout the study. It should be pointed out that the minimum specific energy does not include the energy required to generate excess pressure in the module, or the energy spent on pre-treatment or post-treatment. As can be seen in Fig. S1, the 
PREPRINT Renewable Energy, Volume 105, May 2017, Pages 84-95

DOI: 10.1016/j.renene.2016.12.030

1 minimum work needed theoretically would be $0.81 \mathrm{kWh} / \mathrm{m}^{3}$ of fresh water. This lower limit corresponds to a rate of production that is nearly zero. It can also be seen that, when the recovery rate increases, the specific energy consumption also increases. For the one-stage SWRO system, it has been shown in the literature that the optimal recovery rate for a onestage SWRO unit is around $40 \%$ to $50 \%$ [13]. For these recovery rates, the $\mathrm{SEC}_{\mathrm{RO} \text {,theo }}$ would be between 1.24 to $1.49 \mathrm{kWh} / \mathrm{m}^{3}$, which clearly differs from real values [18,24,25].

\subsubsection{Pressure Retarded Osmosis (PRO)}

In the PRO system, the difference in osmotic pressure between the feed and draw solutions is a key parameter for increasing the energy production. Also, the harvested energy is proportional to the mixing volume. These two parameters should be optimized to guarantee sufficient energy production. Clearly, the energy consumption of the SWRO plant is manifested in the increase of the brine concentration. In other words, it is the minimum energy that should be consumed to extract freshwater from the seawater, which is the theoretical, minimum thermodynamic energy for desalination (i.e. the separation energy equal in magnitude but opposite in sign to the free energy of mixing). In fact, the PRO process is, in practice, acting inversely to the RO process: the feed solution concentrated to brine during the RO process is now diluted under the PRO process. Thus, an equation similar to Eq. (1) can be developed for the PRO process. A recent investigation has introduced the theoretical energy production for the PRO process integrated with SWRO [16], when the brine of the RO unit was used against freshwater from river. Unfortunately, this relation is only valid for a PRO feed solution assumed to be zero. Based on an analogy between RO and PRO, a generalized expression of $\mathrm{SE}_{\mathrm{PRO} \text {,theo }}$ is introduced, taking into account the concentration of the PRO feed solution concentration. Assuming finite dilution in an ideal mixing process, the Specific Energy production, $S E_{P R O, \text { theo }}$, can be calculated as follows:

$S E_{P R O}^{\text {Theo }}=r\left(\frac{\pi_{\text {Draw }}-\pi_{F e e d}}{\pi_{\text {Draw }}}\right)\left(\frac{\pi_{S w}-\pi_{\text {Draw }}}{1-D F}\right)$

where $\pi_{\text {Draw }}$ and $\pi_{\text {Feed }}$ are the osmotic pressures of the PRO feed and draw solutions, respectively. DF and $r$ are, respectively, the dilution factor of the draw solution in the PRO system and the PRO entering flow ratio. Based on the analogy between RO and PRO, DF and $r$ are defined as follows: 
$1 \quad D F=\frac{\Delta Q}{Q_{D}}$

2

$3 \quad r=\frac{Q_{F}}{Q_{D}}$

4

5

where $\Delta \mathrm{Q}, Q_{D}, Q_{F}$ are the PRO permeate, the draw solution and the feed solution flow rates. The boundaries of the permeate flowing across the PRO membrane is $0 \leq \Delta Q \leq Q_{F}$. In other words, the maximum dilution that can be reached with a perfect semi-permeable membrane with no detrimental effects is reached when $\Delta \mathrm{Q}=\mathrm{Q}_{\mathrm{F}}$. The dilution factor, DF, can be described as follows by rearranging Eq.(5):

$D F=f \times r$

where

$f=\frac{\Delta Q}{Q_{F}}$

The parameter $f(0 \leq f \leq 1)$ reflects the fraction of PRO feed flow that crosses the membrane to be mixed with the draw solution. The ratio $r$ is not equal to unity and varies with the recoveries. Then, the dilution factor should be determined based on the fraction $f$ and the recoveries. Using Eq. (7) and (8) for arbitrary values of $f$, the variation of the dilution with $r$ is presented in Fig. 4. As the volume of brine is proportional to the recovery of the first stage, $r$ increases with $\mathrm{Y}_{1}$ to reach the unity at $\mathrm{Y}_{1}=77 \%$. It is clear that the increases in $r$ and $f$ lead to the increase in the dilution factor. The maximum dilution that can be achieved when $f=1$, is equal to $r$. Theoretically, operating at high recoveries optimizes the performance of PRO in terms of energy production thanks to the optimized feed flow ratio $r$. In realistic conditions, high recoveries for seawater desalination are not achievable. Therefore, the choice of input parameters should be studied in detail to guarantee high water production and considerable energy recovery using PRO. 

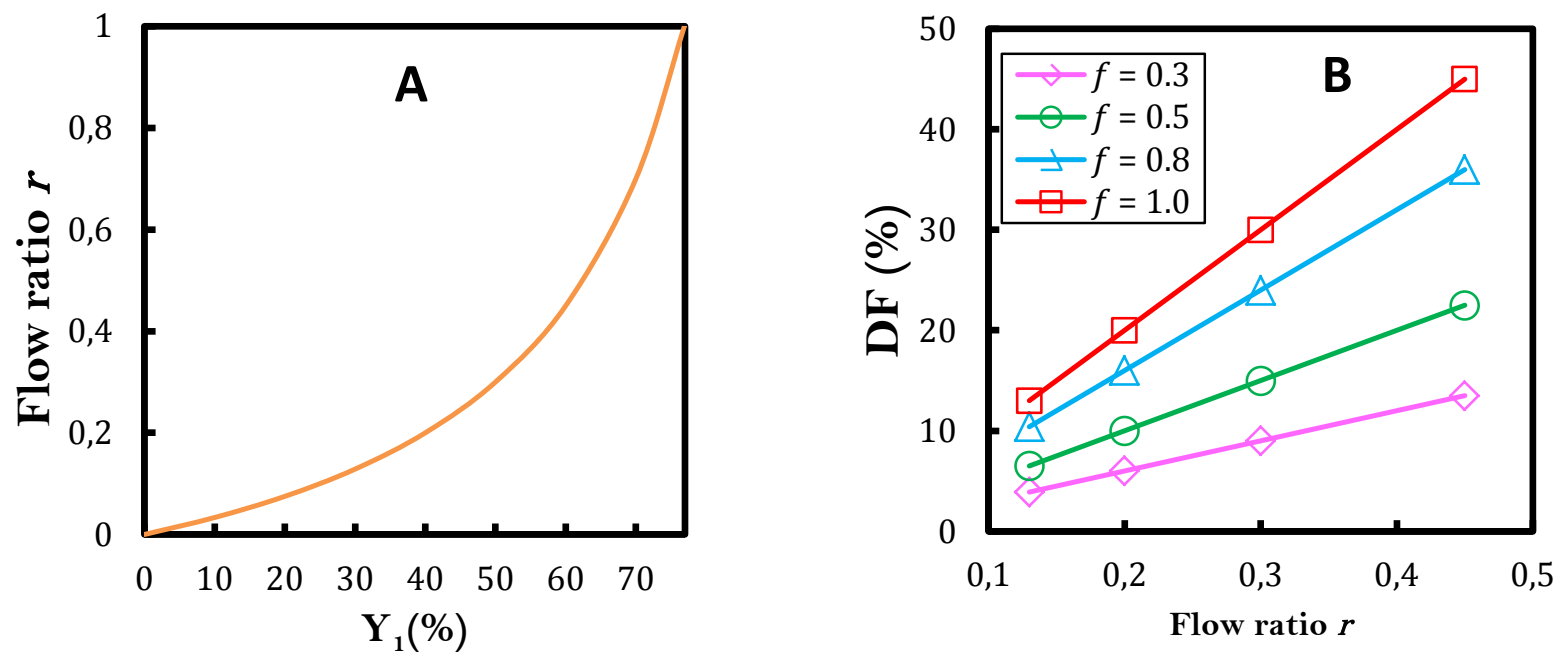

Fig.4: Variation of the dilution factor. (A) represents the variation of $r$ with the recovery of the first stage. (B) shows the variation of the dilution with the feed and draw flow ratio for different feed flow fractions $f$.

\section{a. First configuration}

For the first configuration, Eq.(4) of the Specific Energy production can be written using the operational parameters of the SWRO as follows:

$S E_{P R O, \text { ideal }}^{1}=R_{S} \pi_{S W}\left(\frac{Y_{1}}{1-Y_{1}}\right)\left(\frac{r}{1-D F}\right)\left\{1-\left(1-R_{S}\right)\left(\frac{Y_{1}}{r}\right)\left[\frac{1-Y_{2}\left(1-R_{S}\right)}{1-Y_{1}\left(1-R_{S}\right)}\right]\right\}$

The results of the PRO energy production connected to the SWRO, as described for the first configuration, are shown in Fig.5. In this case, two fractions $f$ were adopted to calculate the energy recovery. As mentioned previously, the increase in the recoveries induces the increase in the dilution. This is justified by the increase of the feed water stream provided by the second RO stage. It can be seen that increasing the dilution factor leads to an increase in the amount of energy produced. This behavior is directly related to the performance of the PRO membrane. Otherwise, the energy produced depends on the operational parameters of the SWRO (recoveries, feed solution concentration, and RO membrane performance). Logically, at high DF, the PRO performance is much better due to the increase of the first stage brine concentration (draw solution of the PRO) and the increase in the amount of feed water that crosses the membrane to the draw water side. It is also clear that the increase in $f$ enhances the energy recovery. Theoretically, at maximum dilutions ( $\mathrm{DF}=45 \%$ when $f=1, \mathrm{DF}=22 \%$ when 
PREPRINT Renewable Energy, Volume 105, May 2017, Pages 84-95

DOI: 10.1016/j.renene.2016.12.030

$1 \mathrm{f}=0.5$ ), PRO produces around $1.01 \mathrm{kWh} / \mathrm{m}^{3}$ and $0.72 \mathrm{kWh} / \mathrm{m}^{3}$, respectively. These values mean that the energy consumption is reduced by $28 \%$ and $20 \%$, respectively.
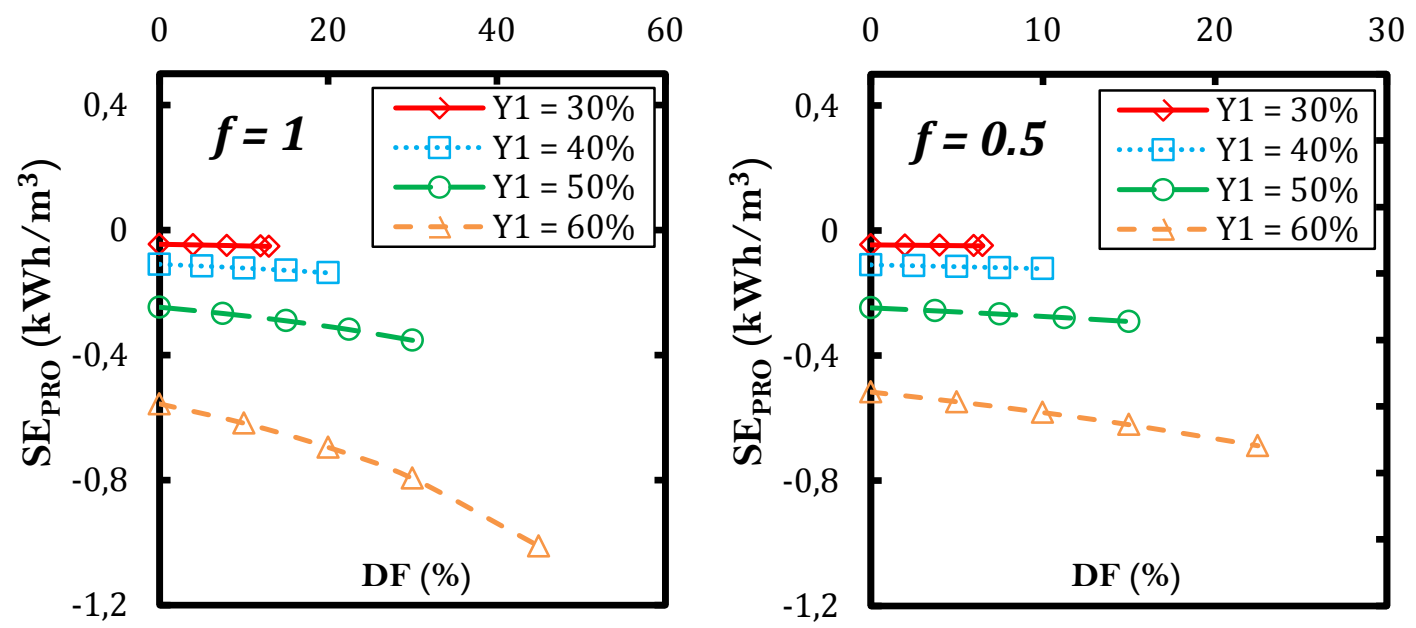

Fig.5: Theoretical Specific Energy production of PRO for the first SWRO-PRO configuration under different dilution factors. The results are fitted for several recoveries of the first SWRO stage. $\mathrm{T}=25^{\circ} \mathrm{C}$.

\section{b. Second configuration}

Clearly, the PRO feed flow is lower than the PRO draw flow for a wide range of $\mathrm{Y}_{1}$ in the first configuration. During the second SWRO-PRO processing, the entering flows of the PRO sub-system $\left(\mathrm{Q}_{\mathrm{F}}\right.$ and $\left.\mathrm{Q}_{\mathrm{D}}\right)$ are maintained equal, thanks to the added pre-treated seawater flow $\mathrm{Q}_{\mathrm{ad}}$ as shown in Fig.3. The amount of added seawater flow respects the following relation:

$Q_{a d}=Q_{s w}\left(1+Y_{1} Y_{2}-2 Y_{1}\right)$

where $\mathrm{Q}_{\mathrm{sw}}$ is the initial seawater flow that enters the first SWRO stage. Consequently, the osmotic pressure of the PRO feed flow, $\mathrm{Q}_{\mathrm{F}}$, depends on the recovery of the first stage. Fig.S2 (Supplementary material) shows the variation of $Q_{a d}$ with respect to $\mathrm{Y}_{1}$ and its effect on the PRO feed osmotic pressure. It can clearly be seen that increasing the recovery of the first stage reduces the amount of the added seawater flow and decreases the osmotic pressure of the PRO entering feed solution due to the increase in the second stage retentate flow. At a recovery of $\mathrm{Y}_{1}=77 \%$, the osmotic pressure of the feed solution reaches its minimum, which corresponds to the osmotic pressure of the second stage retentate, where the addition of $\mathrm{Q}_{\mathrm{ad}}$ is 
PREPRINT Renewable Energy, Volume 105, May 2017, Pages 84-95

DOI: 10.1016/j.renene.2016.12.030

1 annulled. Consequently, at $\mathrm{Y}_{1}=77 \%$, the PRO specific energy production is the same for both

2 SWRO-PRO configurations $\left(S E_{P R O}^{2}=S E_{P R O}^{1}\right)$.

3 Under these conditions, the Specific Energy production can be written using the operational

4 parameters of the SWRO as follows:

5

$6 \quad S E_{P R O}^{2}=\left\{\begin{array}{lr}R_{S} \pi_{S W}\left(\frac{Y_{1}}{1-Y_{1}}\right)\left(\frac{1}{1-D F}\right)\left\{1-\frac{\left(1-R_{S}\right)\left[Y_{1}-Y_{1} Y_{2}\left(1-R_{S}\right)\right]+Y_{1} Y_{2}-2 Y_{1}+1}{1-Y_{1}\left(1-R_{S}\right)}\right\} & 0<Y_{1} \leq 77 \% \\ R_{S} \pi_{S W}\left(\frac{Y_{1}}{1-Y_{1}}\right)\left(\frac{r}{1-D F}\right)\left\{1-\left(1-R_{S}\right)\left(\frac{Y_{1}}{r}\right)\left[\frac{1-Y_{2}\left(1-R_{S}\right)}{1-Y_{1}\left(1-R_{S}\right)}\right]\right\} & 77 \% \leq Y_{1}<100 \%\end{array}\right\}$

8

Fig.6 shows the model results for energy recovered by the PRO using the second configuration for different dilution factors and recoveries. As expected, the increase in the PRO membrane performance leads to a higher energy production. When the recovery of the first SWRO stage increases, the energy recovered also increases due to the increase in the osmotic pressure difference in the PRO module. Compared to the first configuration, the performance of the PRO is relatively better, thanks to the added seawater flow $Q_{a d}$. A comparison between the two configurations is discussed in the next section.

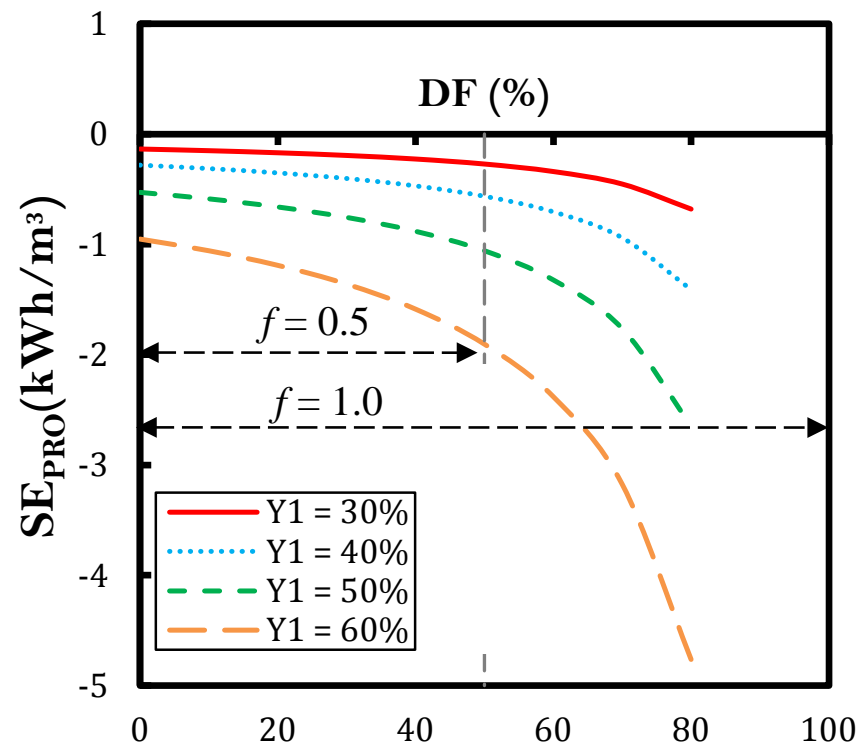

Fig.6: Theoretical Specific Energy production of PRO for the second SWRO-PRO configuration under different dilution factors. The results are fitted for several recoveries of the first SWRO stage. $\mathrm{T}=25^{\circ} \mathrm{C}$. The vertical dashed line indicates the limit of dilution for $f=$ 0.5 . 
PREPRINT Renewable Energy, Volume 105, May 2017, Pages 84-95

DOI: 10.1016/j.renene.2016.12.030

\subsubsection{SWRO-PRO}

The specific energy consumption of the thermodynamically reversible SWRO-PRO system, SEC $C_{\text {SWRO-PRO, id }}^{\text {ideal }}$ obtained by combining the energy consumption of the SWRO sub-system

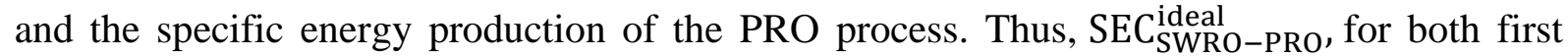
and second configurations, is described as follows [31]:

$\mathrm{SEC}_{\mathrm{SWRO}-\mathrm{PRO}}^{\mathrm{ideal}}=\mathrm{SEC}_{\mathrm{SWRO}}+\mathrm{SE}_{\mathrm{PRO}}$

Fig. 7 shows the evolution of the ideal specific energy of the RO-PRO system as a function of PRO dilution for several $\mathrm{RO}_{1}$ recoveries. As mentioned in the previous section, when the dilution factor increases, the PRO starts to produce energy and the SWRO-PRO system specific energy consumption decreases. For both configurations, positive values of

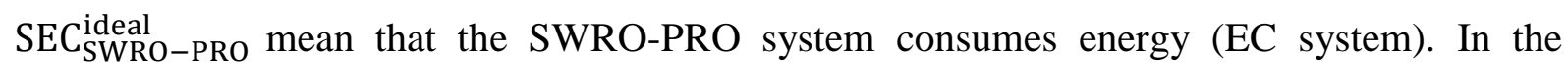
opposite case, negative values mean that the SWRO-PRO system produces energy; in other words, the energy produced by the PRO overcomes the energy consumed by the SWRO (EP system). When the specific energy reaches zero, this point represents an ideal neutral energy system, where the energy consumed by the SWRO is compensated by the energy produced by the PRO. At low dilution, SEC CWWRO-PRO is always positive for each configuration and recovery, which theoretically means that the exiting PRO draw solution flow is inferior to the SWRO feed solution flow. For the first configuration, no scenario corresponds to an EP system (e.g., $\mathrm{SEC}_{\mathrm{RO}} \leq \mathrm{SE}_{\mathrm{PRO}}$ ), and all scenarios show EC systems, as shown in Fig.7-A. Otherwise, the second configuration revealed three scenarios for theoretically possible EP systems (Fig.7-B). Two operating parameters differentiate between the studied configurations: the PRO feed solution concentration and flow. The first configuration provides low a PRO feed concentration with a low feed flow, while the second one guarantees a high feed flow with a considerably high PRO feed concentration (at $\mathrm{Y}_{1}<60 \%$ ). The model results show that the best performance was achieved when the feed flow is maintained equal to the draw solution flow. Therefore, the high osmotic pressure difference between the feed and draw solution is not the only key parameter that guarantees high energy recovery, but also the PRO entering flow ratio, named $r$ here. In fact, when $r$ increases, the SWRO-PRO energy consumption decreases. In addition, regardless of the configuration, it can be clearly seen that the best performance is achieved for high dilution factors, which reveals the strong relationship between the energy and membrane performance. Unfortunately, existing PRO 
PREPRINT Renewable Energy, Volume 105, May 2017, Pages 84-95

DOI: 10.1016/j.renene.2016.12.030

1 full-scale membranes suffer from several drawbacks, such as concentration polarization,

fouling, reverse salt diffusion, and pressure drops, which make, for instance, high dilution unreachable. Thus, in SWRO-PRO hybrid systems, three parameters should be properly controlled, namely: the recovery ratio, the dilution factor, and the PRO entering flow ratio.
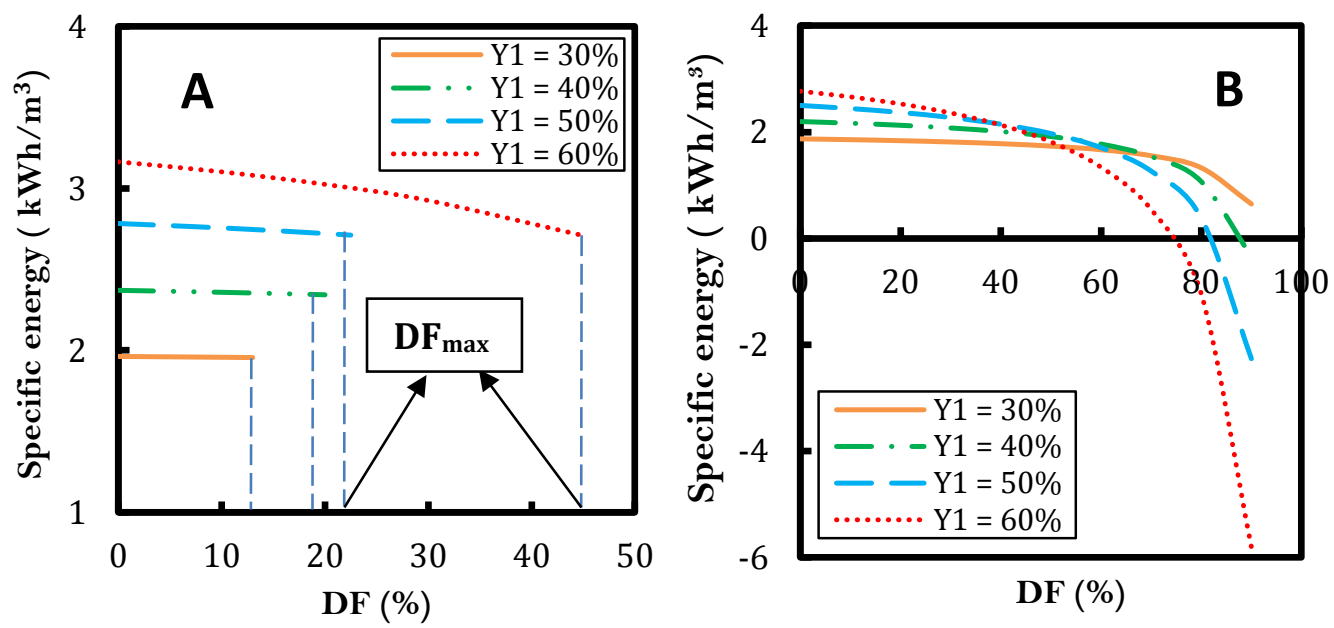

Fig.7: Ideal specific energy consumption of SWRO-PRO system as a function of PRO dilution for several $\mathrm{RO}_{1}$ recoveries. Fig.7.A represents the model results for the SWRO-PRO system operating under the first configuration. Fig.7.B represents the model results for the SWRO-PRO system operating under the second configuration.

\subsection{Modeling the energy consumption of the SWRO-PRO system under realistic conditions}

\subsubsection{PRO model}

Real life SWRO-PRO plants would be less energy efficient than theoretically calculated, due to electrical conversion losses and dissipation. The amount of additional energy required depends on the specific recovery strategy. In addition, the produced energy is proportional to the mixing volume. Consequently, dilution of the draw solution is inevitable. Therefore, the osmotic pressure difference decreases and reduces the performance of PRO. Besides that, previous works had shown that PRO membrane performance is limited by several limiting factors [26,27]. In fact, with a realistic membrane and imperfect hydrodynamics, three phenomena occur to reduce the trans-membrane water flux, as shown in Fig.S4. First, the porous support layer induces internal concentration polarization (ICP), which detrimentally enhances $\pi_{\mathrm{F}, \mathrm{m}}$ by increasing the solute concentration at the feed-membrane interface, thus reducing the trans-membrane driving force. Second, without perfect hydrodynamics in the draw solution flow channel, dilutive external concentration polarization (ECP) develops, which lowers $\pi_{\mathrm{D}, \mathrm{m}}$ and reduces the driving force. Lastly, because the membrane is no longer 
PREPRINT Renewable Energy, Volume 105, May 2017, Pages 84-95

DOI: 10.1016/j.renene.2016.12.030

1 perfectly selective, reverse salt diffusion (RSD) takes place, resulting in uncontrolled mixing

and, therefore, reduced energy extraction in the process. The water flux across the membrane,

$3 J_{w}$, can be defined in terms of the membrane water permeability coefficient, $A$; the osmotic

4 pressure at the draw side of the membrane active layer, $\pi_{D, m}$; the osmotic pressure at the feed

5 side of the membrane active layer, $\pi_{\mathrm{icp}}$; and the hydraulic pressure difference across the

6 membrane:

$7 \quad J_{w}=A\left(\pi_{D, m}-\pi_{i c p}-\Delta P\right)=A\left(\Delta \pi_{m}-\Delta P\right)$

where $\Delta \pi_{m}$ is the osmotic pressure difference across the membrane active layer. Based on film theory, equations have been developed to determine the concentration on either side of the membrane with reverse salt flux and concentration polarization accounted for [25, 26]:

$C_{D, m}=\left(C_{D, b}+\frac{J_{s}}{J_{w}}\right) \exp \left(-\frac{J_{w}}{k_{D}}\right)-\frac{J_{s}}{J_{w}}$

$C_{F, m}=\left(C_{F, b}+\frac{J_{s}}{J_{w}}\right) \exp \left(\frac{J_{W}}{k_{F}}\right)-\frac{J_{S}}{J_{W}}$

$C_{i c p}=\left(C_{F, b}+\frac{J_{s}}{J_{w}}\right) \exp \left(\frac{J_{w}}{k_{F}}\right) \exp \left(J_{w} K\right)-\frac{J_{s}}{J_{w}}$

where $C_{D, b}$ is the bulk draw concentration, $C_{F, b}$ is the bulk feed concentration, and $k_{D}$ and $k_{F}$ are the mass transfer coefficient in the draw and feed sides, respectively. $K$ is the solute diffusion coefficient. The water flux and the salt flux are related by the following relation [27]:

$\frac{J_{s}}{J_{w}}=\frac{B}{A \beta R T}\left(1+\frac{A \Delta P}{J_{w}}\right)$

where $B$ is the salt permeability coefficient, and $\Delta P$ is the hydraulic pressure applied on the draw solution side. Assuming the van't Hoff relationship between osmotic pressure and concentration [25]:

$J_{W}=A\left\{\left(\pi_{D, b}+\frac{B}{A}\left[1+\frac{A \Delta P}{J_{W}}\right]\right) \exp \left(-\frac{J_{W}}{k_{D}}\right)-\left(\pi_{F, b}+\frac{B}{A}\left[1+\frac{A \Delta P}{J_{W}}\right]\right) \exp \left(J_{W} K\right) \exp \left(\frac{J_{W}}{k_{F}}\right)-\Delta P\right\}$

The variations along the membrane's length are often neglected in models designed to simulate bench scale systems because the effect is difficult to observe over very small membrane samples [26]. However, the passage of water through the membrane was followed 
PREPRINT Renewable Energy, Volume 105, May 2017, Pages 84-95

DOI: 10.1016/j.renene.2016.12.030

1 by friction, which should cause some heating of solutions. If the water flow had been created due to the pressure drop on either side of the membrane, this would have led to the loss of part of the energy released. These include flow rates, concentrations and hydraulic pressures, as well as all other variables that are dependent on them. Their local values should be considered for accurate modeling. These spatial variations can be accounted for either by taking an average of inlet and outlet variables, or by considering the membrane as a finite difference model $[26,27]$. To develop a model for full-scale PRO applications, the flat sheet membrane area is divided into segments perpendicular to the water flow, evaluating flow conditions at specific points along the membrane module. In this case, feed and draw solution flows are assumed to be in a co-current flow mode. Fig.S3 illustrates a single segment of a flat sheet PRO membrane. The permeate flow through the PRO membrane $Q_{w}$ can significantly dilute the draw solution concentration $C_{D}$, which results in reduced flux performance compared to the small size test membrane. Such a dilution effect needs to be explicitly accounted for in a flat sheet module. Due to this variation, three main parameters are evaluated at each point along the membrane: the water flux, the pressure and the concentrations. The model development steps are presented in the Supplementary material.

\subsubsection{SWRO model}

The energy consumption of each RO stage in a two-stage RO plant, at the limit of the thermodynamic restriction and in the absence of energy recovery, is developed in [21]:

$\mathrm{SEC}_{\mathrm{RO}_{1}}=\frac{\mathrm{R}_{\mathrm{s}} \pi_{\mathrm{sw}}}{\eta_{\mathrm{P}_{1}} \mathrm{Y}_{1}\left(1-\mathrm{Y}_{1}\right)}$

$\mathrm{SEC}_{\mathrm{RO}_{2}}=\frac{\mathrm{R}_{\mathrm{s}} \pi_{\mathrm{p}}}{\eta_{\mathrm{P}_{2}} \mathrm{Y}_{2}\left(1-\mathrm{Y}_{2}\right)}$

where $R_{S}$ is the salt rejection, and $\eta_{P}$ is the pump conversion. The specific energy cost for RO, in the presence of an energy recovery device (ERD), operating at the limit of the thermodynamic restriction, is:

$S E C_{R O_{1}}^{E R D}=R_{S} \pi_{S w}\left(\frac{1-\eta_{E R D}\left[1-Y_{1}\right]}{\eta_{P} Y_{1}\left[1-Y_{1}\right]}\right)$

where $\eta_{E R D}$ is the efficiency of the energy recovery device. 
PREPRINT Renewable Energy, Volume 105, May 2017, Pages 84-95

DOI: 10.1016/j.renene.2016.12.030

\subsubsection{ERD energy recovery}

The recovery of energy from SWRO systems has been a major factor in the reduction of the cost of desalinated seawater, to a point where it is beginning to offer a challenge to conventional sources. In our case, an ERD is placed after the first RO stage to recover energy from the rejected brine. As mentioned previously, the ERD reduces the pressure of the brine to a suitable value for PRO operational applied pressure ( $\Delta P \approx \frac{\Delta \pi_{m}}{2}$ ). This condition is a key parameter for the optimum performance of the PRO process. In the second configuration, the osmotic pressure of the PRO feed solution is relatively high at low $\mathrm{RO}_{1}$ recoveries, which is not the case for the first configuration. Therefore, the energy recovered using ERD depends on the osmotic pressure that enters the PRO module. As $\pi_{F}$ changes with the recovery, the contribution of ERD in the second configuration also varies regarding the osmotic pressure of the PRO feed solution. Then, the energy recovered by ERD in the second configuration will be much lower than in the first one. Subtracting Eq. (21) from Eq.(19), the energy recovered by the ERD at the thermodynamic restriction is expressed as follows:

$S E_{E R D}^{1}=-R_{S} \pi_{S w}\left(\frac{\eta_{E R D}\left[1-Y_{1}\right]}{\eta_{P} Y_{1}\left[1-Y_{1}\right]}\right)$

$$
S E_{E R D}^{2}=-R_{S}\left[\pi_{S W}-\pi_{F}\right]\left(\frac{\eta_{E R D}\left[1-Y_{1}\right]}{\eta_{P} Y_{1}\left[1-Y_{1}\right]}\right)
$$

The subscripts 1 and 2 refer to the first and second configuration, respectively. The osmotic pressure $\pi_{F}$ in Eq.(23) highlights the effect of the PRO feed osmotic pressure. As can be seen in Fig.S5, the contribution of ERD to the energy recovery is much higher in the first configuration. In fact, in usual RO recovery $\left(40 \% \leq \mathrm{Y}_{1} \leq 60 \%\right)$, the ERD energy recovery is between 1.32 and $2 \mathrm{kWh} / \mathrm{m}^{3}$. Thus, the ERD effectively reduces the SEC by almost 50\%. This result is well-known in the literature [21]. Using the second configuration, the ERD contribution is not significant due to the high pressure required for the PRO process. At high recovery, the ERD energy becomes slightly significant due to the dilution of the added seawater by the rejected water of the second RO stage. 
PREPRINT Renewable Energy, Volume 105, May 2017, Pages 84-95

DOI: 10.1016/j.renene.2016.12.030

\section{3. Results and discussion}

\section{$2 \quad 3.1$. Modeling parameters}

3 The simulations in this study are based on the characteristics of a cellulose acetate flat-sheet membrane used in our previous work, where a power density of $6.2 \mathrm{~W} / \mathrm{m}^{2}$ at 13 bar has been obtained in lab-scale tests using $1.026 \mathrm{M} \mathrm{NaCl}$ solution as the draw solution and $8.55 \mathrm{mM}$ $\mathrm{NaCl}$ solution as the feed solution [25]. The characteristics of the membrane and the hypothetical module parameters are summarized in Table S1. The initial seawater flow was chosen arbitrarily to be $256 \mathrm{~m}^{3} / \mathrm{h}$, which is the real amount of treated water in the SETASWRO plant studied here. The sweater concentration is chosen to be $0.6 \mathrm{M}(35 \mathrm{~g} / \mathrm{L})$. The added flow rate $\mathrm{Q}_{\mathrm{ad}}$ is considered to be pre-treated before being involved in the process. It should be noted that the effect of organic fouling is not considered in this study, so the energy produced may be lower in the presence of feed water charged with natural organic matter (NOM).

\subsection{PRO model results}

The $\mathrm{SE}_{\mathrm{PRO}}$ model was investigated by studying the response of the PRO sub-system after the variation in the effect of the operating conditions (draw and feed solution concentrations). As can be seen in Fig.8, the increase in the draw solution concentration leads to an increase in the energy recovery by the sub-system. On the other hand, the increase in the feed solution concentration is followed by a decrease in the energy. Lastly, the increase in the draw solution temperature improves the performance of the PRO due to the improvement in the effective osmotic pressure and also the intrinsic membrane parameters, such as the water permeability coefficient. These results are in agreement with the model behavior using a lab-scale PRO membrane. Fig.9 illustrates the $\mathrm{SE}_{\mathrm{PRO}}$ in Eq. (S1), corresponding to the PRO model results for the proposed configurations when diluting $\mathrm{RO}_{1}$ brine back to the sea, as a function of the SWRO recovery using the cellulose acetate flat-sheet membrane with the characteristics presented in Table S1. When recovery increases, the draw solution concentration increases, and the $\mathrm{SE}_{\mathrm{PRO}}$ also increases. The minimum $\mathrm{SE}_{\mathrm{PRO}}$ recoveries are $0 \mathrm{kWh} / \mathrm{m}^{3}$ for both configurations. This magnitude increases with $\mathrm{RO}_{1}$ recovery to reach an $\mathrm{SE}_{\mathrm{PRO}}$ production of $0.702 \mathrm{kWh} / \mathrm{m}^{3}$ at $77 \%$ of recovery. Compared to the theoretical $\mathrm{SE}_{\mathrm{PRO}}$ production (Fig. 5), the model produces a specific energy remarkably far from the ideal case. 

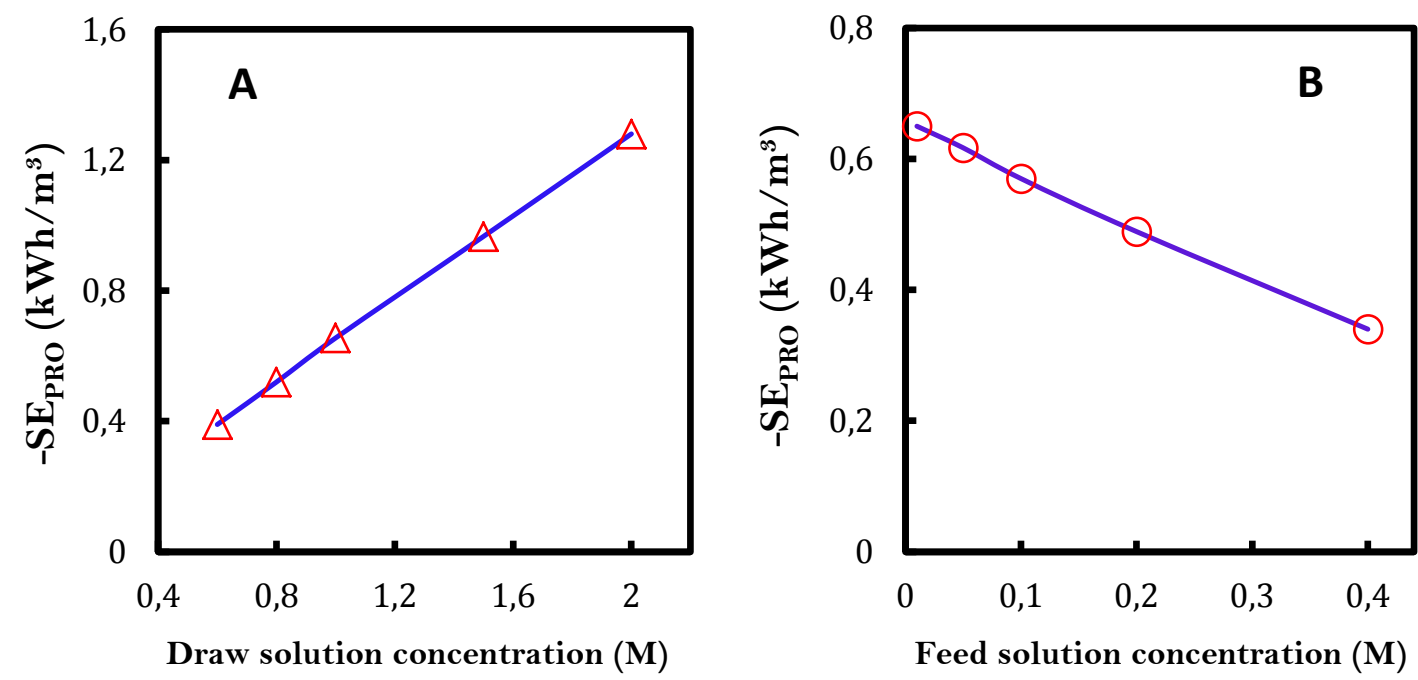

Fig.8 PRO specific energy production ( $\mathrm{SE}_{\mathrm{PRO}}$ ) modeled as a function of feed and draw solution concentrations under optimum PRO hydraulic pressure. Feed and draw solution flows are considered equal. For (A): the feed solution concentration is $8.55 \mathrm{mM}$. For (B): the draw solution is $1.026 \mathrm{M}$. $\mathrm{T}=25^{\circ} \mathrm{C}$.

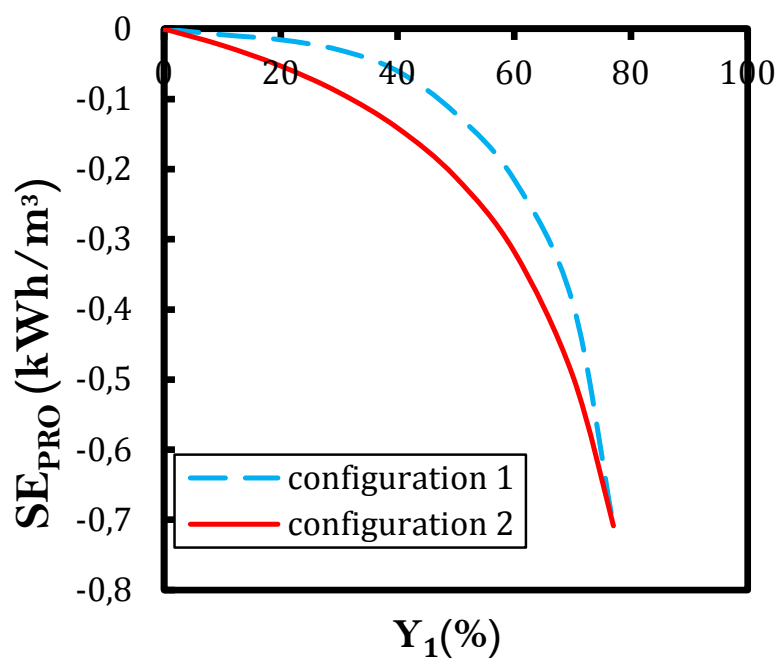

Fig.9: PRO specific energy production ( $\mathrm{SE}_{\mathrm{PRO}}$ ) modeled as a function of $\mathrm{RO}_{1}$ recovery for a cellulose acetate flat-sheet membrane under optimal $\Delta P$ for both proposed configurations.

\subsection{SWRO-PRO model results}

The total energy consumption of the SWRO-PRO system for both configurations is studied here. As mentioned previously, the study only takes into account the effect of the recovery ratio of the first RO stage, so that of the second stage is considered constant $\left(\mathrm{Y}_{2}=70 \%\right)$. According to Fig.10 and Fig.11, the $\mathrm{SE}_{\text {SwRO-PRO }}$ consumption is much lower for the ideal case than for the model results for both configurations. This behavior is due to the fact that the ideal SEPRO production is noticeably higher than the model SEPRo production. Because of the higher starting value of the model $\mathrm{SE}_{\mathrm{SWRO}} \mathrm{PRO}$ and the lower rate at which the model $\mathrm{SE}_{\mathrm{RO}} \mathrm{PRO}$ 
PREPRINT Renewable Energy, Volume 105, May 2017, Pages 84-95

DOI: 10.1016/j.renene.2016.12.030

1 consumption decreases, the model of the SWRO-PRO system is not able to reach energy neutrality $\left(\mathrm{SE}_{\mathrm{SWRO}} \mathrm{PRO}=0\right)$. Fig.10 shows the variation of the modeled energy consumption $\mathrm{SEC}_{\text {SWRO-PRO }}$ with the applied pressure $\Delta P$ under two $\mathrm{RO}_{1}$ recovery ratios without using an

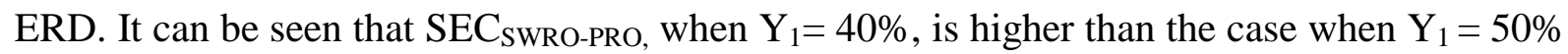
for both configurations. Moreover, at a low recovery ratio, the performance of the second configuration is better than the first one in terms of energy generation and low applied pressure. When the recovery ratio increases, the second configuration shows a better performance than the first, due to the decrease in the PRO feed solution concentration. As a comparison, for (A), the maximum energy recovery is $2.45 \%$ and $4 \%$ when $\mathrm{Y}_{1}=40 \%$ and $50 \%$, respectively. For (B), the energy recovery is $6 \%$ and $8 \%$ when $\mathrm{Y}_{1}=40 \%$ and $50 \%$, respectively. Fig. 16 shows a comparison between the total energy consumption of the SWRO plant with the presence of PRO and ERD. It can be seen that the maximum SE $\mathrm{SwRO}_{\text {-PRO }}$ consumption point for each RO recovery is the point at which there is no PRO sub-system contribution $(\mathrm{DF}=0)$. In other words, this is the maximum $\mathrm{SE}_{\mathrm{RO}}$ consumption for each $\mathrm{RO}$ recovery. For configuration (A), the contribution of the PRO sub-system is very limited at a low $\mathrm{RO}_{1}$ recovery ratio $\left(\mathrm{Y}_{1}<30 \%\right)$, where more than $96 \%$ of the energy recovery is accomplished by ERD. This is due to the low amount of rejected water coming from the second RO stage, which constitutes the feed solution for the PRO sub-system. This result corresponds, theoretically, to less than $20 \%$ of dilution. In addition, the high concentration of the draw solution may induce severe concentration polarization, which reduces the performance of the membrane. Contrary to configuration (A), the contribution of PRO is considerable at a low recovery ratio because the amount of PRO feed solution is provided directly from the pre-treated seawater and remains nearly constant at this range of $\mathrm{RO}_{1}$ recovery ratio $\left(\mathrm{Y}_{1}<20 \%\right.$ ). The contribution of the PRO in the total energy recovered is around $45 \%$. This high value is because of the limited contribution of ERD in this case due to the high PRO feed solution concentration. Also, when the PRO feed flow ratio was maintained equal to unity, the experimental dilution factor increased. For example, when $\mathrm{Y}_{1}=40 \%$, the energy recovered corresponds to $\mathrm{DF}=40 \%$, which is double the dilution in the first configuration case. This result clearly shows the strong relationship between the feed flow ratio and the dilution factor in the PRO process. To summarize, the notable difference between the ideal case and the model case is related to the membrane performance. In fact, to reach high values of dilution, an improvement in the water permeability across the membrane is fundamental. Moreover, avoiding the reverse salt diffusion by reducing the salt permeability of the active layer material enhances the dilution factor. Lastly, improving the 
PREPRINT Renewable Energy, Volume 105, May 2017, Pages 84-95

DOI: 10.1016/j.renene.2016.12.030

1 inner structure of the PRO membrane support layer, to reduce the effect of the internal

2 concentration polarization and optimize the operating conditions in order to minimize the

3 external concentration polarization, is a challenge that can guarantee a better PRO dilution

4 and therefore more recovered energy.
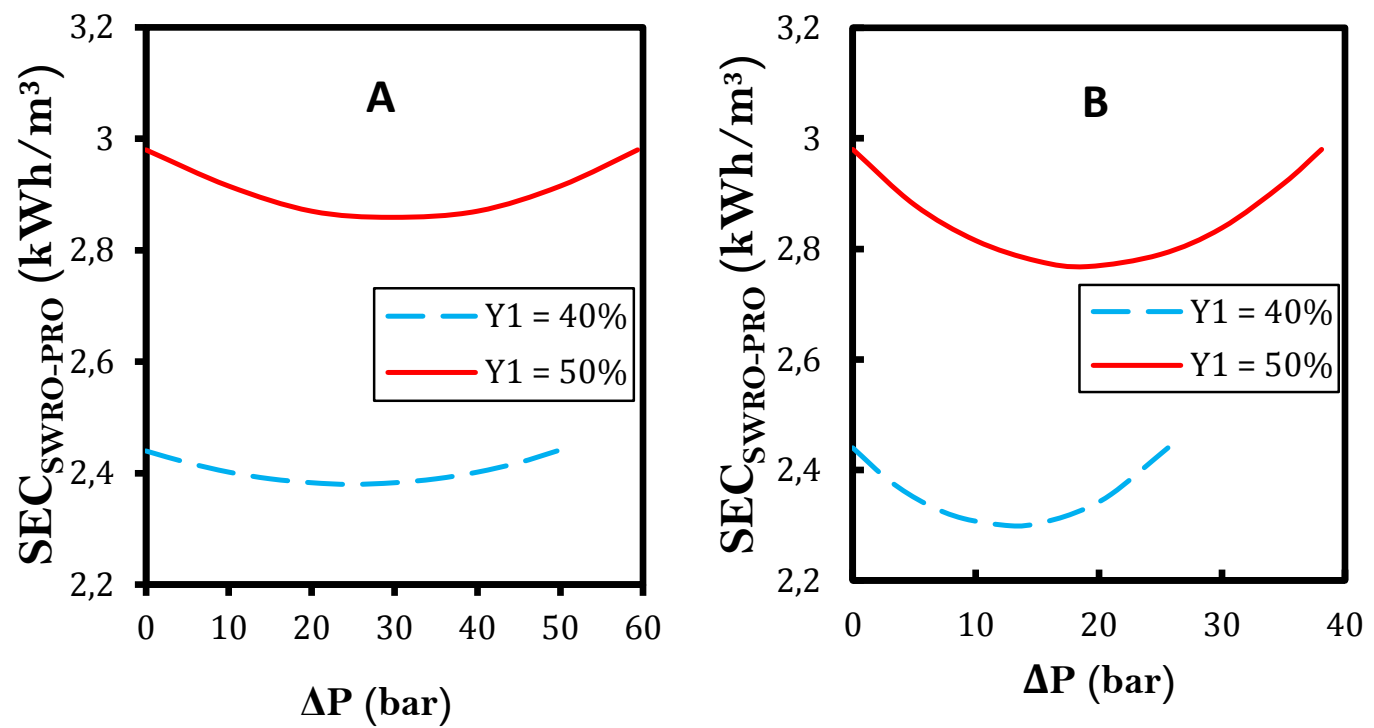

Fig.10: SWRO-PRO specific energy without using ERD, as a function of the applied pressure $\Delta P$ for different $\mathrm{RO}$ recoveries for the model case. (A) represents the result for the first configuration and (B) for the second configuration.

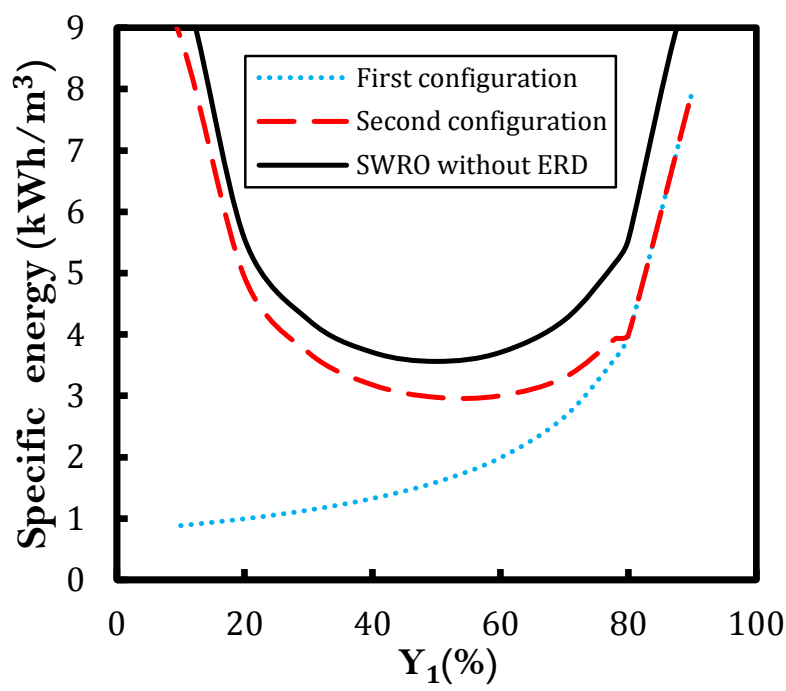

Fig. 11: SWRO-PRO specific energy consumption as a function of the $\mathrm{RO}_{1}$ recovery for the proposed configurations. Pump efficiency, membrane salt rejection, and ERD efficiency were taken as $90 \%$, $98 \%$, and $95 \%$, respectively.

\section{Dilution factor in realistic conditions}

The dilution factor reflects the amount of feed water that is mixed with the draw water to produce energy. This parameter is strongly dependent on the membrane performance and the 
PREPRINT Renewable Energy, Volume 105, May 2017, Pages 84-95

DOI: 10.1016/j.renene.2016.12.030

1 driving force, $\Delta \pi$. In other words, increasing the water flux across the membrane leads to the increase in the dilution. In the ideal case with a perfect membrane, the water flux depends only on the osmotic pressure difference. Then, to achieve high dilutions, the concentrations of feed and draw solutions should be optimized. In realistic conditions, the maximum dilution is not reachable because of several limiting factors, such as the concentration polarization (CP) and reverse salt diffusion (RSD), which reduce the performance of the membrane. The realistic dilution factor is investigated in the current section.

The maximum amount of feed flow that crosses the membrane to be mixed with the draw solution, $\Delta Q_{\max }$, can be calculated using the following equation [32]:

$$
\Delta Q_{\max }=\frac{\sqrt{C_{D, b}}-\sqrt{C_{F, b}}}{\sqrt{C_{D, b}}+\frac{\varnothing}{1-\varnothing} \sqrt{C_{F, b}}} Q_{F}
$$

Eq. (24) is applicable only for an ideal membrane with perfect hydrodynamics. The rearrangement of Eq. (24) using Eqs.(5) and (6) gives the maximum dilution factor:

$$
D F_{\max }=r \frac{\sqrt{C_{D}}-\sqrt{C_{F}}}{\sqrt{C_{D}}+\frac{1}{r} \sqrt{C_{F}}}
$$

where $C_{D}$ and $C_{F}$ are the draw and feed solution concentrations. To introduce the impact of detrimental effects, Eq.(25) is modified by substituting $C_{D}$ and $C_{F}$ by Eqs.(14),(15) and (16) according to the variation of the effective feed and draw concentrations described in Fig.S4 (Supplementary material). Table S2 summarizes the different equations of DF for each case studied. The realistic dilution factor can be determined using the parameters described in Table S1 and the modeling results of section 3.2. To investigate the effect of each detrimental effect, $\mathrm{DF}_{\max }$ is modeled under several operating conditions. In fact, the draw solution is assimilated to the seawater $\mathrm{RO}$ brine concentration $(1.2 \mathrm{M}$ of $\mathrm{NaCl})$ and the feed solution is modified for each studied case from freshwater to river water concentration. The modeling results are presented in Fig.18. The maximum dilution is obtained using an ideal membrane with no reverse salt diffusion $\mathrm{J}_{\mathrm{S}}$ (RSD), concentration polarization, and an advanced state-ofthe-art membrane with perfect hydrodynamics. In this case, the water flux $J_{w}$ is directly proportional to the osmotic pressure difference $=\pi_{D, b}-\pi_{F, b}$. The maximum dilution achievable in this case is $92 \%$. When considering only the effect of the external concentration polarization, which is caused by non ideal hydrodynamics in the draw solution flow channel, 
PREPRINT Renewable Energy, Volume 105, May 2017, Pages 84-95

DOI: 10.1016/j.renene.2016.12.030

1 which induces the dilutive External Concentration Polarization (dilutive ECP) at the draw side and the concentrative External Concentration Polarization (concentrative ECP) at the feed side, the values of the dilution factor decrease by almost $8 \%$ from the ideal case. This behavior is caused by the decrease in the effective osmotic pressure difference from $\Delta \pi$ to $\Delta \pi_{E C P}=\pi_{D, m}-\pi_{F, m}$ (see Fig.S4). With the existence of RSD, the decrease in the DF is around 24\% from the ideal case. In fact, RSD causes the drop in the driving force due to the penetration of salt from the draw to the feed side, which induces a decrease of $J_{w}$. To emphasize the effect of the concentration polarization and internal concentration, the concentration of river water $(0.015 \mathrm{M})$ is considered. Under these conditions, the decrease in the DF reaches $52 \%$. As can be clearly seen, most of the DF reduction is due to the internal concentration polarization with a contribution of $28 \%$. ICP, caused by the accumulation of salt at the active layer/support layer boundary, decreases the driving force from $\Delta \pi$ to $\Delta \pi_{m}=\pi_{D, m}-\pi_{i}$. Consequently, a severe drop occurs in $J_{w ;}$ therefore, DF decreases drastically. As the energy is directly proportional to the dilution, the DF loss from the realistic PRO operation may have a significant impact on the net specific energy recovered from the process. The optimization of the membrane performance is a critical operation to guarantee high energy recovery. It should be pointed out that this study does not consider the effect of organic fouling. In fact, it was shown in a previous study that fouling severely reduces the water flux and therefore the dilution. This energy loss caused by membrane limitations, in conjunction with the pre-treatment energy requirements, pumping energy costs, inefficiencies in the hydro-turbine and pressure exchanger, may limit the amount of energy harvested from the PRO process. Of course, the increase in the concentration difference between the feed and draw solution concentrations may provide a sizable amount of energy using the PRO process. Nevertheless, the increase in the PRO entering solution concentration should be well chosen and treated to avoid the accentuation of the concentration polarization and the reverse salt diffusion, which lead to the decrease in the driving force; the osmotic pressure difference. 


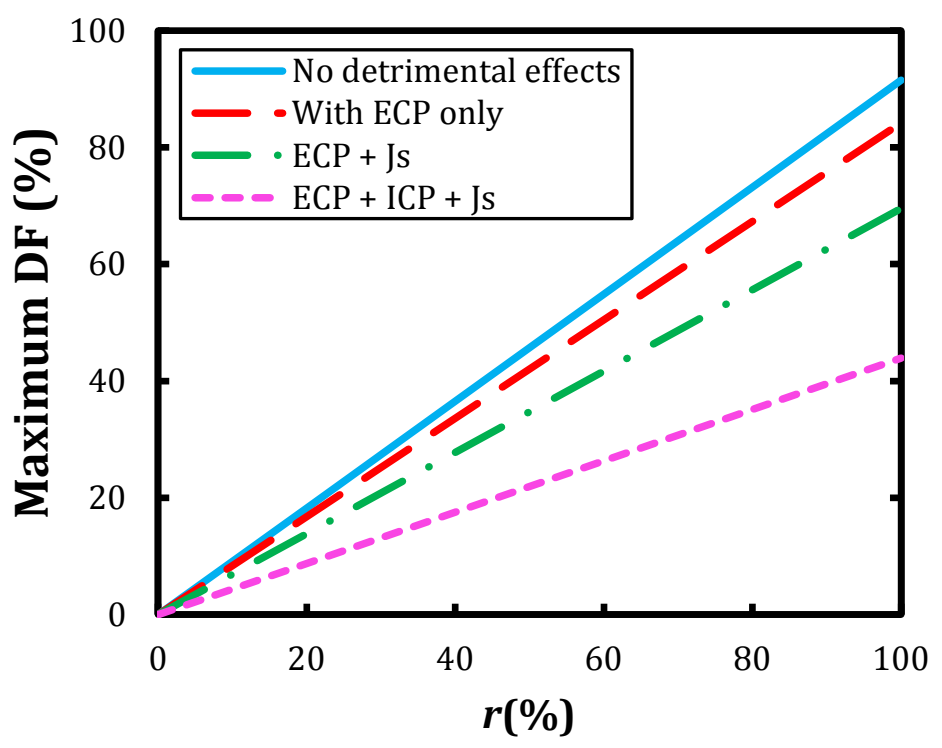

Fig. 12: Modeled dilution factor under different operating conditions and detrimental effects as a function of the feed flow ratio. Dilution factor for ideal membrane with the absence of detrimental effects (solid blue line). Membrane with concentrative External Concentration Polarization (dashed red line). Membrane with salt diffusion and External Concentration

Polarization (green dashed line). Membrane with salt diffusion, Internal Concentration Polarization and External Concentration Polarization (purple dashed line). The draw solution concentration is $0.6 \mathrm{M}$ and the applied pressure $\Delta P$ is $14.5 \mathrm{bar} . \mathrm{T}=20^{\circ} \mathrm{C}$. The characteristics of the membrane are presented in Table S1.

\section{Conclusion}

In the current investigation, two configurations of SWRO-PRO were proposed for energy recovery. The first configuration considers that the brine of the second stage is the PRO feed solution and the brine of the first stage represents the PRO draw solution. For the second configuration, the PRO feed solution is a mixture of the second stage brine and pre-treated seawater. For this, a model describing the evolution of the energy recovery with the SWRO operating conditions was developed and compared to the ideal case model. The results showed that the performance of the PRO was better for the second configuration due to the optimized initial flow ratio. However, for the whole system, the energy recovered from the first configuration was remarkably better for an extended interval of RO recovery, because of the contribution of the energy recovery device. The second part of this investigation deals with the relation between the initial flow ratio $(r)$ and the dilution factor (DF). It was found that the increase in $r$ increases the DF. Then, the DF was modeled for realistic conditions. It was found that the internal concentration 
PREPRINT Renewable Energy, Volume 105, May 2017, Pages 84-95

DOI: 10.1016/j.renene.2016.12.030

polarization is the factor that contributes most to dilution reduction. Consequently, well treated solutions and optimized membrane performance are strongly recommended to achieve a sizable amount of energy from the PRO process. The current work revealed that the energy recovery from the SWRO process using PRO may be optimized not only by the mitigation of the limiting factors (CP, Js, pressure drop, etc...), but also by the well chosen location of PRO integration in the process. This, in the end, depends on the SWRO design, the number of stages, and the characteristics of the output waters. Thus, further work will focus on the integration of multistage PRO in one-stage and multi-stage SWRO processes for water and clean energy production.

\section{ACKNOWLEDGEMENTS}

This work was funded by MiCInn DPI2014-54530-R and FP7 H2OCean (Grant 288145).

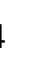

(1)

17


PREPRINT Renewable Energy, Volume 105, May 2017, Pages 84-95

DOI: 10.1016/j.renene.2016.12.030

3

4

\section{LIST OF SYMBOLS}

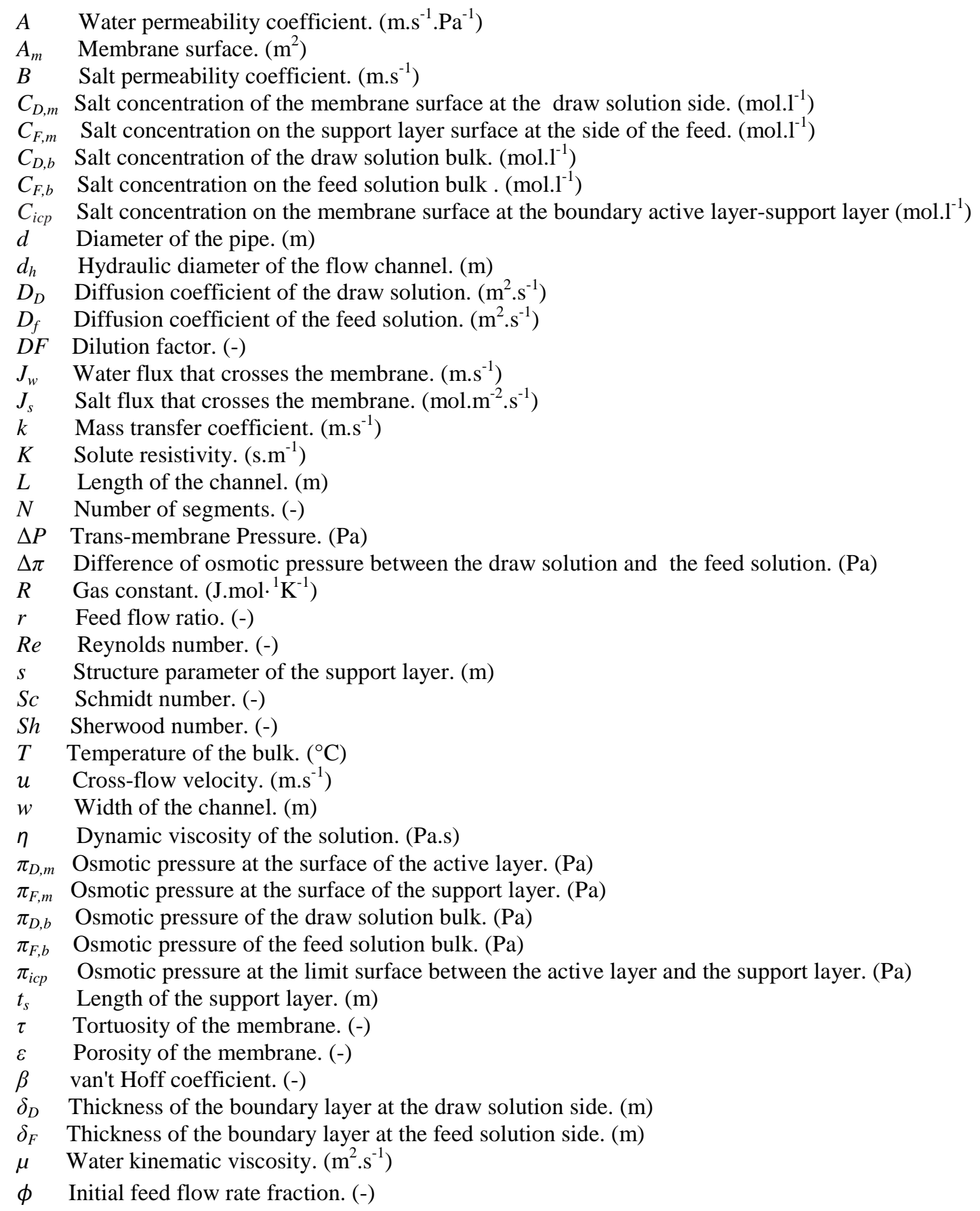


PREPRINT Renewable Energy, Volume 105, May 2017, Pages 84-95

DOI: 10.1016/j.renene.2016.12.030

\section{REFERENCES}

2 [1] Zhou D, Zhu L, Fu Y, Zhu M, Xue L. Development of lower cost seawater desalination processes using nanofiltration technologies - A review. Desalination 2015;376:109_ 116.

[2] Hun Jung Y, Hoon Jeong Y, Choi J, F. Wibisono A, Lee JI, Cheon No H. Feasibility study of a small-sized nuclear heat-only plant dedicated to desalination in the UAE. Desalination 2014:337;83-97.

[3] Ghaffour N, Lattemann S, Missimer T, Choon Ng K, Sinha S, Amy G. Renewable energydriven innovative energy-efficient desalination technologies. Appl Energy 2014;136: 1155-1165.

[4] Ersever I, Ravindran V, Tsai H-H, Pirbazari M. Modeling and design of anaerobic fluidized bed reactor with recycling for denitrification of reverse osmosis concentrates, Chem Eng Sci 2014;108:111-122.

[5] Fuentes-Bargues JL. Analysis of the process of environmental impact assessment for seawater desalination plants in Spain. Desalination 2014;347:166-174.

[6] Li M. Reducing specific energy consumption in Reverse Osmosis (RO) water desalination: An analysis from first principles. Desalination 2011;276:128-135.

[7] Avlonitis SA, Kouroumbas K, Vlachakis N. Energy consumption and membrane replacement cost for seawater RO desalination plants. Desalination 2003;157:151-8.

[8] Altaee A. Forward Osmosis, Potential use in desalination and water reuse. J Membr Sep Technol 2012;1:79-93.

[9] Altaee A, Sharif A. Pressure retarded osmosis: advancement in the process applications for power generation and desalination. Desalination 2015;356:31-46

[10] Touati K, de la Calle A, Tadeo F, Roca L, Schiestel T, Alarcón-Padilla DC. Energy recovery using salinity differences in a multi-effect distillation system. Desalin Water Treat 2014:1-8.

[11] He W, Wang Y, Shaheed M H. Maximum power point tracking (MPPT) of a scale-up pressure retarded osmosis (PRO) osmotic power plant. Appl Energy 2014;136:11551165.

[12] He W, Wang Y, Elyasigomari V, Shaheed MH. Evaluation of the detrimental effects in osmotic power assisted reverse osmosis (RO) desalination. Renew Energy 2016;93:608619. 
PREPRINT Renewable Energy, Volume 105, May 2017, Pages 84-95

DOI: 10.1016/j.renene.2016.12.030

1 [13] Touati K, Tadeo F. Green energy generation by Pressure Retarded Osmosis: State of the art and technical advancement -review. International Journal of Green Energy, 2016 (accepted manuscript).

[14] Saito K, Irie M, Zaitsu S, Sakai H, Hayashi H, Tanioka A, Power generation with salinity gradient by pressure retarded osmosis using concentrated brine from SWRO system and treated sewage as pure water. Desal Water Treat 2012;41:114-21.

[15] Achilli A, Prante JL, Hancock NT, Maxwell EB, Childress AE. Experimental results from RO-PRO: A next generation system for low-energy desalination. Environ Sci Technol 2014;48 (11): 6437-6443.

[16] Prante JL, Ruskowitz JA, AE Childress, Achilli A, RO-PRO, desalination: An integrated low-energy approach to seawater desalination. Appl Energy 2014;120:104-14

[17] Palacin LG, Tadeo F, De Prada C, Touati K. Evaluation of the recovery of osmotic energy in desalination plants by using pressure retarded osmosis. Desalin and Wat Treat 2013;51(1-3):360-365.

[18]Wan CF, Chung TS. Osmotic power generation by pressure retarded osmosis using seawater brine as the draw solution and wastewater retentate as the feed. J Memb Sci 2015;479:148-158.

[19] Wan CF, Chung T-S. Maximize the operating profit of a SWRO-PRO integrated process for optimal water production and energy recovery. Renew Energy 2016;94 :304-313.

[20] Jaber JO, Probert SD, Badr O. Water scarcity: A fundamental crisis for Jordan, Appl Energy 1997;57(2-3):103-127.

[21] Zhu A, Christofides PD, Cohen Y. Minimization of energy consumption for a two-pass membrane desalination: Effect of energy recovery, membrane rejection and retentate recycling. J Memb Sci 2009; 339:126-137.

[22] www.h2ocean-project.eu.

[23]P. Straub A, Lin S, Elimelech M. Module-scale analysis of Pressure Retarded Osmosis: performance limitations and implications for full-scale operation. Environ Sci Technol 2014; 48:12435-12444.

[24]Hoek EMV, Allred J, Knoell T, Jeong BH. Modeling the effects of fouling on full-scale reverse osmosis processes. J Memb Sci 2008; 314: 33-49.

[25] Touati K, Hänel C, Tadeo F, Schiestel T. Effect of the feed and draw solution temperatures on PRO performance: theoretical and experimental study. Desalination 2015; 365:182-195. 
PREPRINT Renewable Energy, Volume 105, May 2017, Pages 84-95

DOI: 10.1016/j.renene.2016.12.030

1 [26] Touati K, Tadeo F. Study of the Reverse Salt Diffusion in pressure retarded osmosis:

Influence on concentration polarization and effect of the operating conditions. Desalination 2016; 389:171-186

[27] Touati K, Tadeo F, Hänel C, Schiestel T. Effect of the operating temperature on hydrodynamics and membrane parameters in pressure retarded osmosis. Desalin Water Treat. (2015) 1-13, http://dx.doi.org/10.1080/19443994.2015.1039600

[28] Naguib MF, Maisonneuve J, Laflamme CB, Pillay P. Modeling pressure-retarded osmotic power in commercial length membranes. Renew Energy 2015; 76:619-627.

[29] Maisonneuve J, Pillay P, Laflamme CB. Pressure-retarded osmotic power system model considering non-ideal effects. Renew Energy 2015; 75:416-424.

[30] Straub AP, Deshmukha A, Elimelech M Pressure-retarded osmosis for power generation from salinity gradients: is it viable?. Energy Environ Sci 2016; 9:31-48

[31] Feinberg BJ, Ramon G, Hoek EMV. Thermodynamic analysis of osmotic energy recovery at a reverse osmosis desalination plant. Environ Sci Technol 2013; 47:2982-89.

[32] Yip NY, Elimelech M. Thermodynamic and energy efficiency analysis of power generation from natural salinity gradients by pressure retarded osmosis. Environ Sci Technol 2012; 46:5230-5239. 